\title{
Neuroparacoccidioidomycosis: Case Report and Literature Review
}

\section{Neuroparacoccidioidomicose: relato de caso e revisão da literatura}

\author{
Marcus Vinicius de Morais ${ }^{1}$ Sérgio Murilo Georgeto ${ }^{2}$ Marcelo Lourenço Haddad ${ }^{2}$ \\ José Guilherme da Silva Amorim² ${ }^{2}$ Luis Guilherme Scaliante ${ }^{2}$ Anderson Luiz de Paula ${ }^{2}$ \\ Igor Vasconcelos de Andrade ${ }^{2}$ Paulo Henrique Pires de Aguiar ${ }^{3}$ \\ ${ }^{1}$ Division of Neurosurgery, Hospital Militar de Área de São Paulo, São \\ Paulo, SP, Brazil \\ 2 Division of Neurosurgery, Santa Casa de Londrina Hospital, Londrina, \\ PR, Brazil \\ ${ }^{3}$ Division of Neurology, Pontifícia Universidade Católica de São Paulo, \\ Address for correspondence Marcus Vinicius de Morais, Hospital \\ Militar de Área de São Paulo, R. Ouvidor Portugal, 230 - Vila \\ Monumento, São Paulo, SP, 01551-010, Brazil \\ (e-mail: moraisneuro@gmail.com).
} Sorocaba, SP, Brazil

Arq Bras Neurocir 2018;37:134-139.

\begin{abstract}
Introduction Paracoccidioidomycosis (PCM) is a systemic mycosis caused by the fungus Paracoccidioides brasiliensis, and it can compromise the central nervous system (CNS) in $10-27 \%$ of all cases.

Case Report A 31-year-old man presented to the Emergency Department with headache, left-sided weakness, clonus at the ankle and a positive Babinski sign. Head computed tomography (CT) and magnetic resonance imaging (MRI) scans showed a $5.1 \times 3.8 \mathrm{~cm}$ lobulated lesion with areas of liquefaction in the right centrum semiovale.

\section{Keywords}

- paracoccidioidomycosis

- central nervous system

\section{Resumo}

Discussion Central nervous system PCM can mimic a brain tumor, and most cases are diagnosed by biopsy of the lesion. The treatment includes antibiotics, but some cases require surgery.

Conclusion Due to high morbimortality rates, the diagnosis must be considered, and early treatment started in patients who live in rural regions endemic for PCM when a ring-enhancing mass associated with perilesional edema is observed on MRI scans.

Introdução Paracoccidioidomicose (PCM) é uma micose sistêmica causada pelo fungo Paracoccidioides brasiliensis e que pode comprometer o sistema nervoso central (SNC) em $10-27 \%$ dos casos.

Relato de caso Um homem de 31 anos é admitido no pronto socorro com cefaleia, hemiparesia esquerda com clonus e presença de sinal de Babinski. As imagens da tomografia computadorizada (TC) de crânio e da ressonância nuclear magnética (RNM) demonstraram uma lesão de $5,1 \times 3,8 \mathrm{~cm}$ no centro semioval direito de aspecto lobulado com áreas de liquefação no centro semioval direito.
\end{abstract}

received

January 29, 2018

accepted

February 27, 2018

published online

April 4, 2018
DOI https://doi.org/

$10.1055 / \mathrm{s}-0038-1641578$. ISSN 0103-5355.
Copyright $\odot 2018$ by Thieme Revinter

Publicações Ltda, Rio de Janeiro, Brazil
License terms

(c) (i) $\ominus$ (\$) 
Discussão Paracoccidioidomicose do SNC pode simular um tumor cerebral, sendo a maioria dos casos diagnosticada por biopsia da lesão. O tratamento inclui antibióticos,

Palavras-chave

- paracoccidioidomycosis

- sistema nervoso central mas alguns casos necessitam de abordagem cirúrgica.

Conclusão Devido à alta morbimortalidade, o diagnóstico deve ser considerado e o tratamento precoce iniciado em pacientes que vivem em áreas rurais endêmicas para PCM e que apresentam lesão com captação anelar de contraste associada a edema perilesional nas imagens de RNM.

\section{Introduction}

Paracoccidioidomycosis (PCM) is a systemic mycosis and chronic granulomatous disease caused by Paracoccidioides brasiliensis, an aerobic and thermally dimorphic fungus. It is acquired by inhalation and can virtually affect any organ. The central nervous system is compromised in $10-27 \%$ of all cases. $^{1-7}$ Neurological symptoms can take place before, simultaneously or after systemic symptoms, and they range from headaches, cranial nerve and motor deficits to seizures and intracranial hypertension, depending on the location of the lesion. ${ }^{1,2,4,5}$ Paracoccidioidomycosis is the most frequent endemic systemic mycosis in Latin America, especially in Brazil, accounting for $\sim 80 \%$ of all registered cases. ${ }^{4,7-9}$

\section{Case Report}

A 31-year-old man presented to the emergency department with headache and left-sided weakness with clonus at the ankle and a positive Babinski signal. The patient referred 13 days of symptoms and no previous surgery, nor hospitalization. He lived in a rural area, and he was a bricklayer. The emergency noncontrast computed tomography (CT) was suggestive of right centrum semiovale lesion and important perilesional edema. The magnetic resonance imaging (MRI) scans showed a $5.1 \times 3.8 \mathrm{~cm}$ lobulated lesion with areas of liquefaction and low intensity on gradient echo $\mathrm{T} 2$ sequence. The white matter and basal ganglia adjacent to the lesion presented a high intensity extending to the right-sided mesencephalon and brainstem. The patient underwent microsurgical resection of the lesion without intercurrences. On the first postoperative day, he presented dilated pupils, no brainstem reflexes and died on the second day after surgery. The biopsy was positive for central nervous system (CNS) PCM.

\section{Discussion}

Paracoccidioidomycosis is a systemic mycosis and an endemic disease in Latin America, with an estimated number of 10 million affected individuals. Brazil represents $\sim 80 \%$ of all cases reported. In one study, anti-P. brasiliensis was detected in $27 \%$ of Brazilian blood donors. ${ }^{10}$ The mycosis affects primarily white and middle-aged people ranging from 20 to 40 years. It is more prevalent in men than women, and more common in rural areas and in rural workers. ${ }^{1-4,7-11}$ Some authors suggest that the gender difference could be explained by an estrogenic inhibitory action on the fungus transformation process. ${ }^{2}$
Paracoccidioidomycosis is also known as South American blastomycosis, but the terminology is not correct because the disease is not restricted to South America. This term may also cause confusion in the international literature with blastomycosis, which is another disease. ${ }^{9}$ Paracoccidioidomycosis is caused by $P$. brasiliensis, a thermally dimorphic and aerobic fungus. At environmental temperature, it is a mold, a saprobic mycelial form that produces slow-growing colonies with chlamydospores visible under the microscope. These microscopic structures are the infectious form of the fungus. The pathogenic agent has been apparent as an oval-to-round yeast cell in mammalian tissues hosts and cultures under the temperature of $37^{\circ} \mathrm{C}$. The microscopic aspect of the pathogenic form is the classic "pilot wheel." The mycosis is acquired by inhalation of the chlamydospores, which transform into the yeast form in the patient's body. Since the host houses the yeast form, PCM is not contagious from person to person. ${ }^{1-3,7,10}$

There are two main clinical forms of PCM. The acute/ subacute form, also called juvenile type, is more common in children and young adults. It is an extra-pulmonary disease with lymphohematogenous dissemination and affects the mononuclear phagocytic system. ${ }^{1,7,8,11,12}$ Due to progressive fungal dissemination and reticuloendothelial system organ hypertrophy, the disease is more aggressive and may present high mortality rates. ${ }^{1,3}$ The symptoms generally appear in 4 to 12 weeks, and the most common ones are lymphadenopathy, digestive manifestations, hepatosplenomegaly and, mainly, skin and bone lesions. The juvenile type represents $3-5 \%$ of PCM cases. ${ }^{7,8}$ The chronic form, also known as adult type, accounts for more than $90 \%$ of all cases. It occurs as reactivation of quiescent foci or as an exogenous reinfection in a male to female ratio of $10-15: 10^{1,7,11,12}$ In the chronic form, the fungus can virtually compromise any organ and the most affected ones are lymph nodes, adrenal gland, liver, bones, but primarily the lungs, mucous membranes and skin. Chronic PCM generally involves more than one organ simultaneously and presents insidious symptoms. In some cases, it may only be diagnosed years after the infection. ${ }^{1-5,7,9,11,12}$ Diagnosis is confirmed by mycological exams (culture, histopathologic and cytopathology exams) and serological tests (the most relevant is gp43 serum marker). ${ }^{2,4,7,9,10}$ It is important to note that the symptoms pattern is different in patients with coinfection of PCM and HIV, making diagnosis more challenging. ${ }^{7,11}$

Neuroparacoccidioidomycosis (NPCM) accounts for 10-36\% of all PCM cases and it is even rarer in females. Considering just the neurologic involvement of the PCM, the male to female ratio 
is $23: 1 .^{2,4,5,9,13}$ In $\sim 21 \%$ of the cases, the onset of neurological symptomatology takes place before systemic symptoms, in 33\% it appears simultaneously, and in $46 \%$ it starts after systemic manifestations. ${ }^{13}$ Exclusive meningeal involvement is considered rare in NPCM, although meningeal extension is not so rare in some case series. ${ }^{6}$ Some case series report mortality rates for NPCM up to $53 \% .^{9}$ Considering the affected areas, two main clinical presentations are described by some authors: $:^{1,3}$ meningitis and pseudotumoral forms. The latter represents $90 \%$ of cases and may be caused by single or multiple granulomas with the presence of $P$. brasiliensis. These lesions are surrounded by a thick capsule and generally exhibit a central necrotic area where the fungus can be found. Reactive gliosis is observed in the neighboring parenchyma, causing the thick capsule observed in NPCM. These capsules do not allow free blood access, which reduces natural defenses. ${ }^{3,14}$ Granulomas can be found in the spinal cord, brainstem, cerebellum, ventricles, and cerebral hemispheres. Some authors cite the cerebral hemispheres as the most common place of PCM granulomas due to hematogenous dissemination in the CNS. ${ }^{1,5,6,9,13}$ The percentages vary extremely according to authors, with supratentorial lesions being reported from $47-100 \%$ of cases and infratentorial lesions from $21-42.4 \%$ of cases. Simultaneously supra- and infratentorial involvement varied from $23-37.5 \%$ of all cases. Multiple parenchymal lesions accounts for $23-75 \%$ of cases and the number of lesions ranges from 1 to 10 . $^{1-3,5,6,8,9,13,15,16}$ Leptomeningeal and/or pachymeningeal involvement represent the meningeal presentation, and it manifests by meningeal signs. Spinal cord involvement is rare and accounts for $0.6 \%$ of all cases of PCM and 4\% of NPCM. The most frequently involved spinal cord levels are thoracic, in 58\%, cervical, in 25\%, and both in $8 \%$ of cases. ${ }^{1,6,8,13}$

The symptoms vary depending on the location of the lesion. Different authors suggest different main symptomatology. The most common manifestation cited in the literature are motor symptoms and signs ( 50\% of cases), intracranial hypertension (near $50 \%$ of cases), seizures (in a quarter of all cases), cerebellar symptoms and signs (in $20-25 \%$ of cases) and paresthesia and cognitive symptoms (in $\sim 20 \%$ of cases). Medullary symptoms and signs represent less than $10 \%$ of cases, and their clinical features suggest transverse myelitis, spinal cord compression, and signs of spinal root compression or conus medullaris involvement. Some authors also cite weight loss in $46.1 \%$ of cases. $^{1-6,8,9,13,16,17}$ One case series study reported a high morbidity among patients with NPCM, with $\sim 63 \%$ of the patients developing sequelae in the follow-up: $60 \%$ of them remained with sensitive deficits, $40 \%$ with motor deficits or seizures and $20 \%$ with gait disturbances. ${ }^{16}$

The radiologic evaluation of NPCM is based on contrastenhanced head CT and MRI scans. There is no pattern for CT in NPCM. One study suggests that granulomatous or pseudotumoral presentations have a biphasic CT aspect based on the length of the disease. Images obtained before 5 months of symptoms have single or multiple round lesions presenting hypodense signal, ring-enhancement after contrast, and fainted perilesional edema with or without hydrocephalus. After 5 months, lesions may present a hyperdense signal and ring-like contrast enhancement. The granulomas mean size is $23 \mathrm{~mm}$ (range 12-45 mm). ${ }^{3}$ Other authors also depict different CT scan patterns. Some less frequent are multiloculated or calcified lesions, in which ring enhancement and intralesional septation may also be present. No bone lesions were found in NPCM. ${ }^{1-3,5,15,18}$ A study with 1 and 2-year CT scan follow-up demonstrated that nearly a third of the lesions were calcified after 23 months. This work also described that the size and edema intensity were the first signs to improve under treatment. ${ }^{8}$ Due to the lack of typical and characteristic features, a fungal granuloma in CT scan can mimic or be misdiagnosed as a glioma, tuberculoma, lymphoma, meningioma, cholesteatoma, metastasis, pyogenic and non-pyogenic abscesses, infarct in a subacute phase, or resolving hematoma. ${ }^{3,5,18}$ Magnetic resonance imaging is also important for NPCM evaluation, since it is the best method to analyze meningeal or parenchymal lesions. The granulomas in MRI are lesions with peripheral hyperintense signal on T1WI and hypointense signal in T2WI in most cases. Some lesions may present hypo-to-isointense on T1WI. Necrosis and ring enhancement is found in most cases, but heterogeneous enhancement is also possible. Magnetic resonance spectroscopy may demonstrate lipid peaks. Restricted diffusion is not expected. Enhancing lesions in post-gadolinium in T1WI may persist in the first few months. ${ }^{1,5,6,14,18-20}$

Very few authors analyzed the cerebrospinal fluid (CSF) alterations in NPCM. In one study, liquor analysis and culture were performed in 17 patients, but there were no conclusive findings. ${ }^{3}$ In another study, five patients underwent lumbar puncture for CSF analysis. A double-immunodiffusion test presented positive titers of 1:64 in only one of them. ${ }^{8}$ In a systemic review, liquor analysis contributed in diagnosis by immunological tests in $16.3 \%$ of cases, direct microscopic examination in $1.9 \%$ and CSF culture in $1.2 \% .^{5}$ Other authors also suggest that looking for the fungus is time consuming, not efficient, and rarely positive. ${ }^{2,13}$ The CSF is usually limpid and presents normal pressure during lumbar puncture. Total protein (TP) may be normal or elevated up to $200 \mathrm{mg} / \mathrm{dL}{ }^{2,5}$ Increased CSF TP was found in $61 \%$ of patients in one study. Gammaglobulin was also at higher levels in $63 \%$ of cases. ${ }^{2}$ Authors report low or normal levels of glucose. ${ }^{2,5}$ Enzyme linked immunosorbent assay (ELISA) anti-gp43 was positive in $89 \%$ of the CSF samples in one study, but other authors noted that gp43 cross-reacts with serum from patients with aspergillosis and histoplasmosis. ${ }^{21,22}$

In sum, when systemic PCM is not already diagnosed, NPCM is not part of the differential diagnosis and is confirmed after CNS biopsy. It confirmed the diagnosis in 35\%92.3\% of cases. Patients underwent stereotaxic or open surgery biopsy. ${ }^{3,5,9}$

For moderate or severe cases of PCM, in which NPCM is included, the recommended treatment consists in two parts: the first one is an induction phase until the acute phase laboratory parameters return to normal and the clinical symptoms are controlled. The second step is the maintenance phase. Usually, the induction phase is based on intravenous drugs and once the treatment achieves the maintenance phase, it can be changed to oral drugs. ${ }^{12}$ The duration of the treatment depends on the clinical response, 
Table 1 Patients data from literature review of Neuroparacoccidioidomycosis

\begin{tabular}{|c|c|}
\hline Data & Quantity (\%) \\
\hline Total cases reported & $44(100)$ \\
\hline \multicolumn{2}{|l|}{ Sex } \\
\hline Male & $39(88.6)$ \\
\hline Female & $5(11.4)$ \\
\hline \multicolumn{2}{|l|}{ Symptoms } \\
\hline Headache & $24(54.5)$ \\
\hline Cerebellar symptoms & $15(34.1)$ \\
\hline Hemiplegia or hemiparesis & $13(29.5)$ \\
\hline Ocular motility or visual deficits & $10(22.7)$ \\
\hline Intracranial hypertension & $9(20.4)$ \\
\hline Generalized seizure & $9(20.4)$ \\
\hline Consciousness alterations & $9(20.4)$ \\
\hline Speech deficits & $5(11.4)$ \\
\hline Sensitivity deficits & $4(9.1)$ \\
\hline Meningism & $3(6.9)$ \\
\hline Spinal cord compression symptoms & $3(6.9)$ \\
\hline Focal seizure & $1(2.3)$ \\
\hline Cervical pain & $1(2.3)$ \\
\hline Fever & $1(2.3)$ \\
\hline \multicolumn{2}{|l|}{ Time of symptoms onset (months) } \\
\hline One or less & $13(29.5)$ \\
\hline Two or more & $8(18.2)$ \\
\hline Not informed & $21(47.7)$ \\
\hline \multicolumn{2}{|l|}{ Primary site of PCM } \\
\hline Oral & $6(10.2)$ \\
\hline Skin & $9(15.3)$ \\
\hline Lungs & $25(42.4)$ \\
\hline Others & $4(6.8)$ \\
\hline Not informed or not identified & $15(25.4)$ \\
\hline \multicolumn{2}{|l|}{ Associated comorbidity } \\
\hline HIV & $2(4.5)$ \\
\hline \multicolumn{2}{|l|}{ Lesion location } \\
\hline Supratentorial & $29(48.3)$ \\
\hline Infratentorial & $28(46.7)$ \\
\hline Spinal cord & $3(5)$ \\
\hline \multicolumn{2}{|l|}{ Lumbar puncture } \\
\hline $\begin{array}{l}\text { Patients submitted to } \\
\text { the procedure }\end{array}$ & $9(20.5)$ \\
\hline Diagnosis confirmed by CSF & $4(9.1)$ \\
\hline \multicolumn{2}{|l|}{ Antibiotic treatment } \\
\hline Sulfamethoxazole/Trimethoprim & $27(41.5)$ \\
\hline Amphotericin B & $13(20)$ \\
\hline Sulfadiazine & $12(18.5)$ \\
\hline
\end{tabular}

Table 1 (Continued)

\begin{tabular}{|l|l|}
\hline Data & Quantity (\%) \\
\hline Itraconazole & $5(7.7)$ \\
\hline Ketoconazole & $3(4.6)$ \\
\hline Ampicillin & $1(1.5)$ \\
\hline Chloramphenicol & $1(1.5)$ \\
\hline Intrathecal Amphotericin B & $1(1.5)$ \\
\hline Fluconazole & $1(1.5)$ \\
\hline Antituberculosis drugs & $1(1.5)$ \\
\hline Morbimortality & \\
\hline Death & $7(15.9)$ \\
\hline Hemiplegia or hemiparesis & $6(12.8)$ \\
\hline Sensitivity alterations & $3(6.4)$ \\
\hline Visual deficits & $2(4.3)$ \\
\hline Seizure & $2(4.3)$ \\
\hline Spinal cord injury & $2(4.3)$ \\
\hline Cerebellar complications & $1(2.1)$ \\
\hline
\end{tabular}

Abbreviations: CSF, cerebrospinal fluid; HIV, human immunodeficiency virus; PCM, paracoccidioidomycosis.

but some authors suggest schemes lasting from 12 to 84 months, ceasing medication in the absence of disease activity and upon improvement of clinical, laboratory and radiological conditions. ${ }^{1,2,4,5,8,9,12}$ The treatment is based on anti-P. brasiliensis drugs, and most studies report sulfamethoxazole-trimethoprim (SMZ-TMP) association as first therapeutic option, combined or not with fluconazole. Amphotericin B (AmB) was used by some authors in the initial treatment of severe cases. ${ }^{2,4,8,12,16}$

Sulfamethoxazole-trimethoprim has adequate CSF levels, but its main disadvantage is the need for long-term treatments in moderate to severe cases, surpassing 12 months. Some of the recommended posology is $480-960$ mg every 8-12 hours, and severe cases may demand higher intravenous doses during the induction phase. Due to a theoretical possibility of resistance to SMZ-TMP and the good CNS penetration of fluconazole, a study suggests the use of this drug in association with SMZ-TMP. Fluconazole is also recommended when hepatic enzymes are elevated or there is any intolerance to sulfas or $\mathrm{AmB}$. The recommended dose for fluconazole is $200 \mathrm{mg} / \mathrm{day}$ until the end of treatment. ${ }^{8,12}$

The starting dose of AmB ranges from 5-10 mg/day, but it can be increased to $1 \mathrm{mg} / \mathrm{kg} / \mathrm{day}$, if necessary, in severe cases of NPCM. Although it is a highly active fungistatic and fungicidal compound, some authors describe low drug levels in CNS, and therefore suggest administering it intrathecally when there is no response to the intravenous therapy. If prescribed intrathecally, it is necessary to also administer hydrocortisone (25-30 mg or the equivalent dose of dexamethasone) to avoid arachnoiditis.,12 Other antifungal drugs considered by various authors are voriconazole and itraconazole. ${ }^{2,4,5,8,9,12,16,23}$ 
There are some discussions over the usage of corticosteroids for PCM and NPCM. The rationale for their use is to reduce the inflammatory response, which may be harmful if not checked. Although previously not recommended, a recent study $^{24}$ described the use of corticosteroids adjunct therapy (aCST) for some NPCM cases. The drugs used were prednisone and dexamethasone. The dose for the former was $1 \mathrm{mg} / \mathrm{kg} / \mathrm{day}$ for 10 days and then tapered off until removal, within 30 days. The dose for dexamethasone was $16 \mathrm{mg} /$ day for 6 days and then tapered off in 7 days. Dexamethasone can be prescribed for oral intake or intravenous administration. Hydrocortisone is also cited as a good alternative. It is important to note the necessity to rule out subclinical associated infections, such as tuberculosis and strongyloidiasis, which may become severe and disseminated with corticotherapy. The authors of this study also depicted that microbiological response to the antifungals remain unaffected during aCST. Another study noted that PCM is a common cause of adrenal insufficiency, therefore requiring corticosteroid administration due to stress or infection episodes that can induce life-threatening conditions. ${ }^{12,24}$

Surgical intervention may be necessary if the patient presents elevated intracranial pressure caused or not by hydrocephalus, presence of mass effect caused by a granuloma, unresponsive clinical treatment, or progressive spinal cord compression. ${ }^{1,2,24}$

Case reports about NPCM are growing over the years, and most data are recent, showing the importance of the disease in the differential diagnosis when the patient meets risk factors and epidemiology. As a literature review, for this paper we also searched the keywords "neuroparacoccidioidomycosis" and "central nervous system paracoccidioidomycosis" in PubMed and selected the case series reports published since 1998 that included these terms. There were 24 reports, but 6 were excluded due the lack of specific and individualized information about the cases. The 18 reports left provided 44 cases. ${ }^{1,4,16,17,23,25-37}$ The information available were categorized and the results are in -Table 1 .

In conclusion, NPCM is a rare disease with a broad differential diagnosis in imaging. Due its high morbidity and mortality rates, NPCM should be considered in patients who live in rural regions endemic for PCM when a ring-enhancing mass associated with perilesional edema is observed on MRI scans. Early diagnosis and treatment are important to reduce the devastating effects of the disease. Sulfamethoxazole-trimethoprim associated with fluconazole appears to be a feasible treatment option. Amphotericin B should be considered in severe cases, and aCST can potentially help in the management of these situations. Surgery must be considered depending on lesion location and patient's clinical and neurological conditions. ${ }^{1,3-6,8,9,16,24}$

\section{Conflicts of Interest}

The authors declare that there are no conflicts of interest

\section{References}

1 Elias J Jr, dos Santos AC, Carlotti CG Jr, et al. Central nervous system paracoccidioidomycosis: diagnosis and treatment. Surg Neurol 2005;63(01, Suppl 1):S13-S21, discussion S21
2 de Almeida SM. Central nervous system paracoccidioidomycosis: an overview. Braz J Infect Dis 2005;9(02):126-133

3 Gasparetto EL, Liu CB, de Carvalho Neto A, Rogacheski E. Central nervous system paracoccidioidomycosis: imaging findings in 17 cases. J Comput Assist Tomogr 2003;27(01):12-17

4 Isolan GR, Vieira DM, Hehn F, Antunes AC. Paracoccidioidomycosis simulating brain tumor. Surg Neurol Int 2014;5(05):134

5 Pedroso VSP, Vilela MdeC, Pedroso ERP, Teixeira AL. [Paracoccidioidomycosis compromising the central nervous system: a systematic review of the literature]. Rev Soc Bras Med Trop 2009;42(06):691-697

6 Reis F, Collier PP, Souza TF, et al. Neuroparacoccidioidomycosis (NPCM): magnetic resonance imaging (MRI) findings. Mycopathologia 2013;175(1-2):181-186

7 Shikanai-Yasuda MA, Telles Filho FdeQ, Mendes RP, Colombo AL, Moretti ML. Guidelines in paracoccidioidomycosis. Rev Soc Bras Med Trop 2006;39(03):297-310

8 Francesconi F, da Silva MT, Costa RL, et al. Long-term outcome of neuroparacoccidioidomycosis treatment. Rev Soc Bras Med Trop 2011;44(01):22-25

9 Fagundes-Pereyra WJ, Carvalho GT, Góes AM, das Chagas Lima e Silva F, de Sousa AA. Central nervous system paracoccidioidomycosis: analysis of 13 cases. Arq Neuropsiquiatr 2006;64(2A):269-276

10 Maluf MLF, Pereira SRC, Takahachi G, Svidzinski TIE. Prevalence of paracoccidioidomycosis infection determined by sorologic test in donors' blood in the Northwest of Paraná, Brazil. Rev Soc Bras Med Trop 2003;36(01):11-16

11 Almeida FA, Neves FF, Mora DJ, et al. Paracoccidioidomycosis in Brazilian Patients With and Without Human Immunodeficiency Virus Infection. Am J Trop Med Hyg 2017;96(02):368-372

12 Shikanai-Yasuda MA. Paracoccidioidomycosis Treatment. Rev Inst Med Trop São Paulo 2015;57(19, Suppl 19):31-37

13 de Almeida SM, Queiroz-Telles F, Teive HAG, Ribeiro CEL, Werneck LC. Central nervous system paracoccidioidomycosis: clinical features and laboratorial findings. J Infect 2004;48(02):193-198

14 da Rocha AJ, Maia ACM Jr, Ferreira NPDF, do Amaral LLF. Granulomatous diseases of the central nervous system. Top Magn Reson Imaging 2005;16(02):155-187

15 Rodacki MA, De Toni G, Borba LA, Oliveira GG. Paracoccidioidomycosis of the central nervous system: CT findings. Neuroradiology 1995;37(08):636-641

16 Pedroso VSP, Lyon AC, Araújo SA, Veloso JMR, Pedroso ERP, Teixeira AL. Paracoccidioidomycosis case series with and without central nervous system involvement. Rev Soc Bras Med Trop 2012;45(05):586-590

17 França MC Jr, de Castro R, Balthazar MLF, Faria AV, Cendes F. Focal status epilepticus as the first manifestation of paracoccidioidomycosis. Eur J Neurol 2005;12(01):73-74

18 Naik V, Ahmed FU, Gupta A, et al. Intracranial Fungal Granulomas: A Single Institutional Clinicopathologic Study of 66 Patients and Review of the Literature. World Neurosurg 2015;83(06):1166-1172

19 Magalhaes AC, Caramelli P, Silva ED, et al. Magnetic resonance imaging in intracranial paracoccidioidomycosis. J Neuroimaging 1993;3(04):216-219

20 Jorge LA Jr, Yamashita S, Trindade AP, et al. Pseudotumoral neuroparacoccidioidomycosis of the posterior fossa: A case report and review of the literature. Surg Neurol Int 2017;8(08):76

21 Sandhu GS, Aleff RA, Kline BC, da Silva Lacaz C. Molecular detection and identification of Paracoccidioides brasiliensis. J Clin Microbiol 1997;35(07):1894-1896

22 de Almeida SM, Queiroz-Telles F, Doi EM, Ono M, Werneck LC. Anti-gp43 antibodies in the cerebrospinal fluid of patients with central nervous system involvement by paracoccidioidomycosis. Am J Clin Pathol 2002;118(06):864-868

23 Villa LA, Tobón A, Restrepo A, et al. Central nervous system paracoccidioidomycosis. Report of a case successfully treated with itraconazol. Rev Inst Med Trop São Paulo 2000;42(04):231-234 
24 Benard G, Campos AF, Netto LC, et al. Treatment of severe forms of paracoccidioidomycosis: is there a role for corticosteroids? Med Mycol 2012;50(06):641-648

25 do Valle ACF, Skacel M, Costa RLB, Ribeiro CT, Montagna NA, da Cruz LCH. A case report of intraspinal paracoccidioidomycosis. Rev Inst Med Trop São Paulo 1998;40(03):203-207

26 Silva-Vergara ML, Rocha IH, Vasconcelos RR, et al. Central nervous system paracoccidioidomycosis in an AIDS patient: case report. Mycopathologia 2014;177(1-2):137-141

27 Pereira GH, Lanzoni VPB, Beirão EM, Timerman A, Melhem MdeS. Disseminated Fungal Infection With Adrenal Involvement: Report of Two Hiv Negative Brazilian Patients. Rev Inst Med Trop São Paulo 2015;57(06):527-530

28 Corti M, Trione N, Risso D, et al. Disseminated paracoccidioidomycosis with a single brainstem lesion. A case report and literature review. Neuroradiol J 2010;23(04):454-458

29 Teive HAG, Zanatta A, Germiniani FMB, Almeida SM, Werneck LC. Holmes' tremor and neuroparacoccidioidomycosis: a case report. Mov Disord 2002;17(06):1392-1394

30 Finamor LP, Muccioli C, Martins MC, Rizzo LV, Belfort RJr. Ocular and central nervous system paracoccidioidomycosis in a pregnant woman with acquired immunodeficiency syndrome. Am J Ophthalmol 2002;134(03):456-459
31 Teixeira MJ, Fonoff ET, Machado LdosR, Nóbrega JPS, StermanNeto H, Amorim RL. Paracoccidioidomycosis: intralesional therapy. Arq Neuropsiquiatr 2010;68(03):458-459

32 Lorenzoni PJ, Chang MR, Paniago AMM, Salgado PR. Paracoccidioidomycosis meningitis: case report. Arq Neuropsiquiatr 2002; 60(04):1015-1018

33 da Silva CE, Cordeiro AF, Gollner AM, Cupolilo SMN, QuesadoFilgueiras M, Curzio MF. Paracoccidioidomycosis of the central nervous system: case report. Arq Neuropsiquiatr 2000;58 (3A):741-747

34 Rojas-Jaimes J, Castillo Cordova R, Tárraga Gonzales D. Paracoccidiomicosis in the central nervous system: a case report. Rev Peru Med Exp Salud Publica 2015;32(01):183-186

35 dos Santos VM, Xavier RM, Cortes JA, Osterne EMC, de Worisch Ferreira Lopes M. Pseudotumoral neuroparacoccidioidomycosis: one case report. Mycopathologia 2008;166(03):155-158

36 Duarte ALWP, Baruffa G, Terra HBG, Renck DV, de Moura D, Petrucci C. [Systemic paracoccidioidomycosis with central nervous system involvement]. Rev Soc Bras Med Trop 1999;32(04): 439-442

37 Lambertucci JR, Lana-Peixoto MA, Pitella JEH. [Paracoccidioidomycosis of the central nervous system]. Rev Soc Bras Med Trop $2001 ; 34(04): 395-396$ 